\title{
Effects of different land use types on potential evapotranspiration in the Beijing-Tianjin-Hebei region, North China
}

\author{
HAN Jingyan ${ }^{1,2}$, "ZHAO Yong ${ }^{2}$, WANG Jianhua ${ }^{2}$, ZHANG Bing ${ }^{3}$, ZHU Yongnan², \\ JIANG Shan ${ }^{2}$, WANG Lizhen ${ }^{2}$
}

1. Institute of Hydrology and Water Resources, Department of Hydraulic Engineering, Tsinghua University, Beijing 100084, China;

2. State Key Laboratory of Simulation and Regulation of Water Cycle in River Basin, China Institute of Water Resources and Hydropower Research, Beijing 100038, China;

3. Tianjin Key Laboratory of Water Resources and Environment, Tianjin Normal University, Tianjin 300387, China

\begin{abstract}
Potential evapotranspiration $\left(\mathrm{ET}_{0}\right)$ is vital for hydrologic cycle and water resource assessments as well as crop water requirement and irrigation demand assessments. The Beijing-Tianjin-Hebei region (Jing-Jin-Ji)-an important, large, regional, economic community in China has experienced tremendous land use and land cover changes because of urbanisation and ecological restoration, affecting the hydrologic cycle and water resources of this region. Therefore, we analysed $\mathrm{ET}_{0}$ in this region using climate data from 22 meteorological stations for the period 1991-2015 to understand this effect. Our findings show that $\mathrm{ET}_{0}$ increased significantly at a rate of $7.40 \mathrm{~mm}$ per decade for the region. Based on the major land use type surrounding them, the meteorological stations were classified as urban, farmland, and natural stations using the 2015 land use dataset. The natural stations in the northern mountainous area showed a significant increase in $\mathrm{ET}_{0}$, whereas most urban and farmland stations in the plain area showed a decrease in $\mathrm{ET}_{0}$, with only a few of the stations showing an increase. Based on the different $\mathrm{ET}_{0}$ trends for different land use types, these stations can be ranked as follows: urban stations (trend value: -4.663 to -1.439 ) > natural stations (trend value: 2.58 to 3.373 ) > farmland stations (trend value: -2.927 to -0.248 ). Our results indicate that land use changes affect meteorological parameters, such as wind speed and sunshine duration, which then lead to changes in $\mathrm{ET}_{0}$. We noted that wind speed was the dominant parameter affecting $\mathrm{ET}_{0}$ at all the natural stations, and wind speed and sunshine duration were the dominant parameters affecting $\mathrm{ET}_{0}$ at most of the urban stations. However, the main controlling parameters affecting $\mathrm{ET}_{0}$ at the farmland stations varied. These results present $\mathrm{a}$
\end{abstract}

Received: 2018-05-12 Accepted: 2018-11-15

Foundation: National Key Research and Development Program of China, No.2016YFC0401407; National Natural Science Foundation of China, No.51379216; National Science Foundation for Distinguished Young Scholars, No.51625904; International Science \& Technology Cooperation Program of China, No.2016YFE0102400

Author: Han Jingyan (1984-), PhD, specialized in hydrology and water resource. E-mail: hanjy16@mails.tsinghua.edu.cn "Corresponding author: Zhao Yong (1977-), PhD, E-mail: zhaoyong@iwhr.com 
scope for understanding land use impact on $\mathrm{ET}_{0}$, which can then be applied to studies on sustainable land use planning and water resource management.

Keywords: land use; potential evapotranspiration; meteorological parameters; water resource management; Jing-Jin-Ji region

\section{Introduction}

Water is the vital basic resource for the sustainable development of any region's agriculture, society and economy. However, in current times, water scarcity has become a serious global issue with a dramatic increase in water demand. Furthermore, water deficiency has become increasingly evident with increasing land and water use (Liu et al., 2008).

With the rise of water deficiency, potential evapotranspiration $\left(\mathrm{ET}_{0}\right)$-an important component of the hydrological cycle-has been widely used for water deficiency evaluation and water resource management (Huang et al., 2014). Additionally, evapotranspiration (ET) is a key variable of the climate system, as it affects the energy and water balance of a surface (Boisier et al., 2014). Global and regional land surfaces rapidly undergo changes with increasing urbanisation, agricultural practices and ecological restoration projects (Li et al., 2017). Such land use changes influence the water balance of a region, affecting the available water supply and ET (Kundu et al., 2017). Changes in ET reflect the potential effects of different land use types on the climate, hydrological cycle and water resources of a region.

Land use or land use practices have different effects on ET in different parts of a region. Deforestation may result in a decrease in ET (Olchev et al., 2008), and agricultural land is noted to exhibit higher actual ET values than urban land (Liu et al., 2010). In China, ET in farmland areas has been observed to be more than that in urban areas, showing a significant increase of $98 \mathrm{~mm}$ per year, because of cropland management measures, such as irrigation (Liu et al., 2008). While agricultural activities have contributed to a significant increase in ET (Zou et al., 2017), a decrease in $\mathrm{ET}_{0}$ was noted in farmland areas that are highly dependent on irrigation, such as that in Northwest China (Han et al., 2016). Thus, $\mathrm{ET}_{0}$ may vary for different land use types on a regional scale.

China has experienced rapid land use changes during the last century, and this process is expected to continue in the future (Liu et al., 2008). The Jing-Jin-Ji region (Beijing Municipality, Tianjin Municipality and Hebei Province), North China, is a semi-humid and semi-arid region, facing water resource issues because of rapid urbanisation, extensive agricultural activities and a dramatic increase in water demand (Dong et al., 2008). Therefore, water security has become more important in this region. Although the water supply capacity of the Jing-Jin-Ji region has improved as the implementation of the South-North Water Transfer Project, water shortage crisis still exists due to the continuous increase of population in the region (Feng and Liu, 2006). Consequently, an analysis of $\mathrm{ET}_{0}$ for different land use types in this region is required to understand the regional water resource behaviour and for water resource management.

Little is known about changes in $\mathrm{ET}_{0}$ for different land use types in the Jing-Jin-Ji region. Therefore, in this study, we (1) analyse the variation in $\mathrm{ET}_{0}$ for different land use types, (2) study the relationship between land use and $\mathrm{ET}_{0}$ at meteorological stations and (3) discuss the response of meteorological parameters and $\mathrm{ET}_{0}$ to different land use types. The conclu- 
sions will enhance our understanding of the impact of land use on $\mathrm{ET}_{0}$, thus providing a basis for regional water resource management.

\section{Materials and methods}

\subsection{Study area}

The Jing-Jin-Ji region $\left(36^{\circ} 02^{\prime}-42^{\circ} 38^{\prime} \mathrm{N}, 113^{\circ} 25^{\prime}-119^{\circ} 51^{\prime} \mathrm{E}\right)$ is located in North China (Figure 1a). Its altitude ranges from 2 to $2836 \mathrm{~m}$ and its general topography consists of mountains, plateaus and plains, with high-relief areas in the northwest and low-relief areas in the southeast. The western part of this region contains the Loess Plateau and the Taihang Mountains, the northern part contains the Mongolian Plateau and the Yanshan Mountains, and the eastern and southeastern parts contain the North China Plain. The Jing-Jin-Ji region is a large, regional, economic community and the fastest-developing region in China. Climatically, it is a semi-humid and semi-arid region, part of the East Asian monsoon region. The annual mean precipitation is about $539 \mathrm{~mm}$, and the annual evaporation is about $470 \mathrm{~mm}$ (Liu et al., 2010; Zhao et al., 2014).

$114^{\circ} \mathrm{E} \quad 115^{\circ} \mathrm{E} \quad 116^{\circ} \mathrm{E} \quad 117^{\circ} \mathrm{E} \quad 118^{\circ} \mathrm{E} \quad 119^{\circ} \mathrm{E} \quad 120^{\circ} \mathrm{E}$

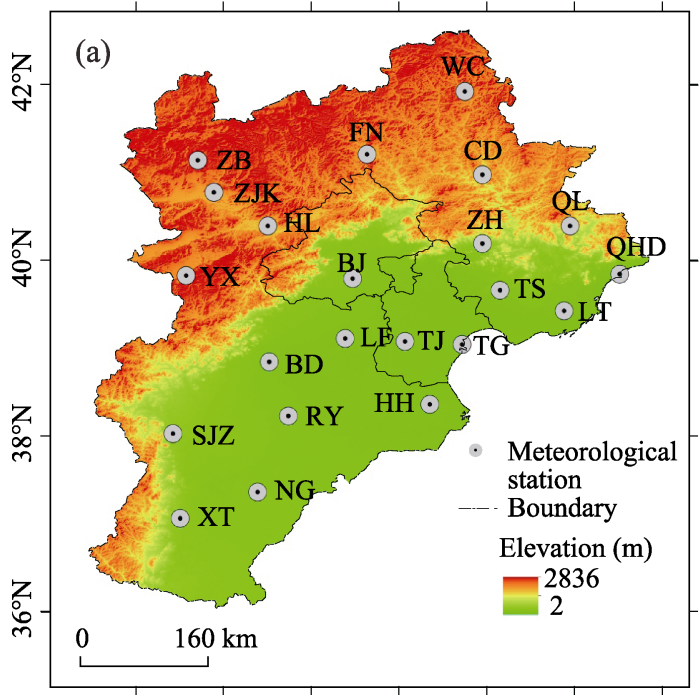

$114^{\circ} \mathrm{E} \quad 115^{\circ} \mathrm{E} \quad 116^{\circ} \mathrm{E} \quad 117^{\circ} \mathrm{E} \quad 118^{\circ} \mathrm{E} \quad 119^{\circ} \mathrm{E} \quad 120^{\circ} \mathrm{E}$

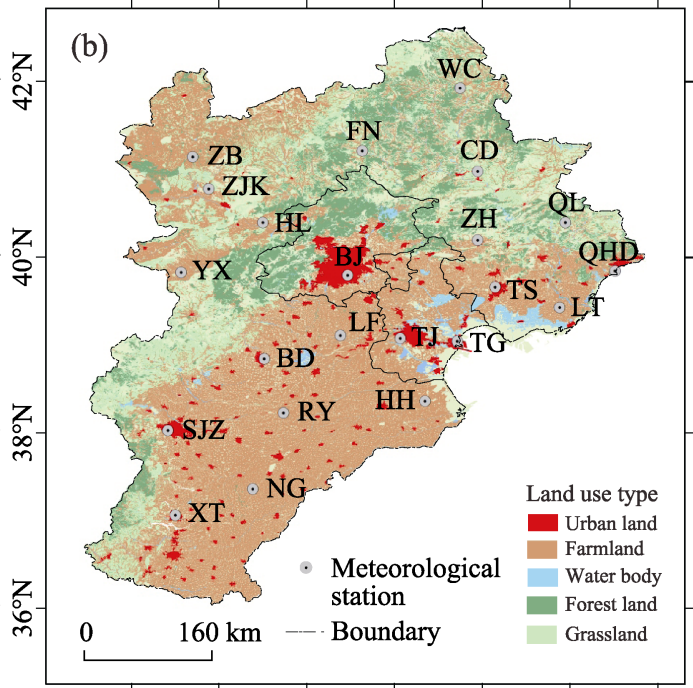

Figure 1 Location of the meteorological stations (a) and land use patterns in 2015 (b) for the Jing-Jin-Ji region

\subsection{Meteorological data}

Daily meteorological data of 22 national meteorological stations from 1991 to 2015 were downloaded from the National Climate Center of the China Meteorological Administration (http://data.cma.cn). The original variables used to calculate $\mathrm{ET}_{0}$ were mean air temperature $\left(T_{\text {mean }}\right)$, minimum air temperature $\left(T_{\min }\right)$, maximum air temperature $\left(T_{\max }\right)$, sunshine duration $(S D)$, relative humidity $(R H)$ and wind speed $\left(U_{10}\right)$.

\subsection{Land use data and classification of stations}

We obtained land use data from the Data Center for Resources and Environmental Sciences 
Table 1 Location of 22 national meteorological stations in the Jing-Jin-Ji region

\begin{tabular}{|c|c|c|c|c|c|}
\hline Station No. & Station & Latitude $\left({ }^{\circ} \mathrm{N}\right)$ & Longitude $\left({ }^{\circ} \mathrm{E}\right)$ & Elevation (m) & Dominant land use type \\
\hline 53399 & Zhangbei (ZB) & 41.15 & 114.70 & 1393.3 & Farmland \\
\hline 53593 & Yuxian (YX) & 39.83 & 114.57 & 909.5 & Farmland \\
\hline 53698 & Shijiazhuang (SJZ) & 38.03 & 114.42 & 81.0 & Urban \\
\hline 53798 & Xingtai (XT) & 37.07 & 114.50 & 77.3 & Urban \\
\hline 54308 & Fengning (FN) & 41.22 & 116.63 & 661.2 & Natural \\
\hline 54311 & Weichang (WC) & 41.93 & 117.75 & 842.8 & Natural \\
\hline 54401 & Zhangjiakou (ZJK) & 40.78 & 114.88 & 724.2 & Urban \\
\hline 54405 & Huailai (HL) & 40.40 & 115.50 & 536.8 & Farmland \\
\hline 54423 & Chengde (CD) & 40.98 & 117.95 & 385.9 & Natural \\
\hline 54429 & Zunhua $(\mathrm{ZH})$ & 40.20 & 117.95 & 54.9 & Urban \\
\hline 54436 & Qinglong (QL) & 40.40 & 118.95 & 227.5 & Natural \\
\hline 54449 & $\begin{array}{l}\text { Qinhuangdao } \\
\text { (QHD) }\end{array}$ & 39.85 & 119.52 & 2.4 & Urban \\
\hline 54511 & Beijing (BJ) & 39.80 & 116.47 & 31.3 & Urban \\
\hline 54518 & Langfang (LF) & 39.12 & 116.38 & 9.0 & Farmland \\
\hline 54527 & Tianjin (TJ) & 39.08 & 117.07 & 2.5 & Urban \\
\hline 54534 & Tangshan (TS) & 39.67 & 118.15 & 27.8 & Urban \\
\hline 54539 & Laoting (LT) & 39.43 & 118.88 & 10.5 & Farmland \\
\hline 54602 & Baoding (BD) & 38.85 & 115.52 & 17.2 & Urban \\
\hline 54606 & Raoyang (RY) & 38.23 & 115.73 & 19.0 & Farmland \\
\hline 54623 & Tanggu (TG) & 39.05 & 117.72 & 4.8 & Urban \\
\hline 54624 & Huanghua $(\mathrm{HH})$ & 38.37 & 117.35 & 6.6 & Farmland \\
\hline 54705 & Nangong (NG) & 37.37 & 115.38 & 27.4 & Farmland \\
\hline
\end{tabular}

of the Chinese Academy of Sciences. The resolution of the land use map was $1 \mathrm{~km}$, and land use datasets for the year 2015 were used to identify different land use types (Figure 1b). Depending on the area ratio of a land use type within a 5-km radius around the station site, the stations were classified into three types: natural, farmland and urban stations. Natural stations had the sum of farmland and urban land with a percentage less than $50 \%$, In other words, the percentage of water bodies, forests and grasslands in this region was $>50 \%$. The percentage of cultivated land with respect to farmland stations was $>50 \%$ and that of urban land with respect to urban stations was $>50 \%$ (Han et al., 2012; Xu et al., 2015).

\subsection{Calculation of $E T_{0}$}

The FAO56 Penman-Monteith equation, considered to be the most accurate, was applied to calculate daily $E T_{0}$. The annual $E T_{0}$ value was obtained by summing up the daily values. The equation is expressed as follows (Allen et al., 1998):

$$
E T_{0}=\frac{0.408 \Delta\left(R_{n}-G\right)+\gamma(900 /(T+273)) U_{2}\left(e_{S}-e_{a}\right)}{\Delta+\gamma\left(1+0.34 U_{2}\right)}
$$


where $E T_{0}$ is the daily reference ET rate $\left(\mathrm{mm} \mathrm{day}^{-1}\right), R_{n}$ denotes net radiation at the ground surface $\left(\mathrm{MJ} \mathrm{m}^{-2}\right.$ day $\left.^{-1}\right), G$ represents soil heat flux density $\left(\mathrm{MJ} \mathrm{m}^{-2}\right.$ day $\left.^{-1}\right), T$ denotes mean daily air temperature at a $2-\mathrm{m}$ height $\left({ }^{\circ} \mathrm{C}\right), U_{2}$ denotes wind speed at a 2-m height $\left(\mathrm{m} \mathrm{s}^{-1}\right), e_{s}$ represents saturation vapour pressure $(\mathrm{kPa}), e_{a}$ represents actual vapour pressure $(\mathrm{kPa}), \Delta$ denotes the slope of the vapour pressure curve $\left(\mathrm{kPa}^{\circ} \mathrm{C}^{-1}\right)$ and $\gamma$ is the psychometric constant $\left(\mathrm{kPa}{ }^{\circ} \mathrm{C}^{-1}\right)$.

The original wind speed data was obtained at a $10-\mathrm{m}$ height, which then required conversion to wind speed at a 2-m height. The equation for this conversion is expressed as follows:

$$
u_{2}=u_{z} \frac{4.87}{\ln (67.8 z-5.42)}
$$

where $z$ is the measurement height above the ground surface $(\mathrm{m}), u_{z}$ is the wind speed at a $z$-m height $\left(\mathrm{m} \mathrm{s}^{-1}\right)$.

\subsection{Trend and relative contribution analysis}

The Mann-Kendall (MK) trend test is widely used for long-term time series trend analysis in hydrology and meteorology (Jhajharia et al., 2009; Huo et al., 2013; Wang et al., 2015). In this method, the equations for calculating the test statistic $S$ and the standardised test statistic $Z$ are as follows:

$$
\begin{gathered}
S=\sum_{i=1}^{n-1} \sum_{j=i+1}^{n} \operatorname{sgn}\left(x_{j}-x_{i}\right) \\
\operatorname{sgn}\left(x_{j}-x_{i}\right)= \begin{cases}1 & \text { if }\left(x_{j}-x_{i}\right)>0 \\
0 & \text { if }\left(x_{j}-x_{i}\right)=0 \\
-1 & \text { if }\left(x_{j}-x_{i}\right)<0\end{cases} \\
\sigma_{s}^{2}=\frac{n(n-1)(2 n+5)-\sum_{p=1}^{q} t_{p}\left(t_{p}-1\right)\left(2 t_{p}+5\right)}{18} \\
Z= \begin{cases}\frac{s-1}{\sigma_{s}} & \text { if } s>0 \\
0 & \text { if } s=0 \\
\frac{s+1}{\sigma_{s}} & \text { if } s<0\end{cases}
\end{gathered}
$$

where $Z$ is used to estimate the statistical trend. A positive $Z$ value indicates an increasing trend in the time series, while a negative $Z$ value indicates a decreasing trend. There is a significant trend in the time series when $|Z|>Z_{1-\alpha / 2}$. The tested significance level $\alpha$ was set to 0.05 in this study, and at this significance level, the value of $Z_{1-\alpha / 2}$ was 1.96 .

To assess the effect of meteorological variables on $\mathrm{ET}_{0}$, linear regression was used to establish a multiple regression equation, and the relative contribution of each meteorological variable to be $\mathrm{ET}_{0}$ was noted to be a ratio of each variable's regression coefficient to the sum 
of all of the variables' regression coefficients (Li et al., 2014; Wang et al., 2016; Han et al., 2018).

\section{Results and discussion}

\subsection{Urban, farmland and natural stations}

The meteorological stations in the Jing-Jin-Ji region were classified into three types-urban, farmland and natural stations. If the area of urban land or farmland in the 5-km radius of the station was equal to or greater than $50 \%$, the associated station was referred to as an urban station or a farmland station, respectively. If non-urban and non-farmland areas in the 5-km radius of the stations were $>50 \%$, these stations were included under natural stations. Based on the 2015 land use dataset, we noted 10 urban stations, 8 farmland stations and 4 natural stations (Figure 2). The four natural stations, namely Qinglong, Chengde, Fengning and Weichang, were located in the northern mountainous area of the Jing-Jin-Ji region. The proportions of the natural area for each of these stations were $76.16 \%, 73.27 \%, 61.96 \%$ and $68.30 \%$, respectively. The forests in the northern mountainous area have been planted under the Three-North Shelter Forest Program (Jiang et al., 2015). Furthermore, the western and northern mountainous areas are being considered as ecological conservation areas under the coordinated development of the Jing-Jin-Ji region.

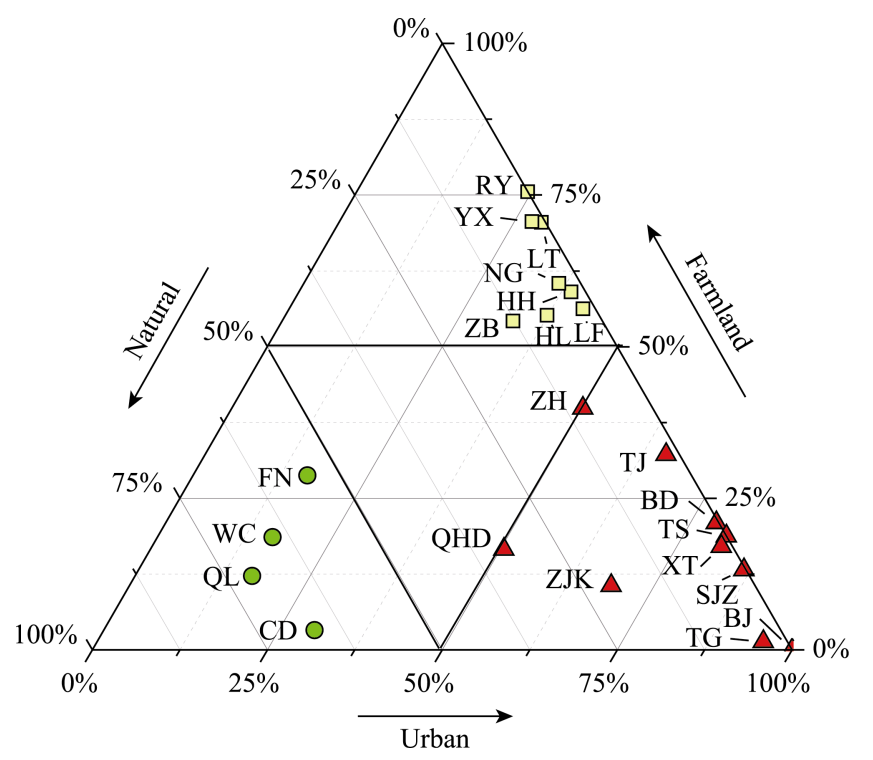

Figure 2 Urban, farmland and natural stations classified using 2015 land use dataset for the Jing-Jin-Ji region

Most of the urban stations are located in the plain area. The urban area proportions for six of the urban stations were $>75 \%$ and those for four of the stations were between $50 \%$ and $75 \%$. As the most urbanised station, the proportion of the urban area around Beijing station was $100 \%$, and those around Zunhua and Qinhuangdao stations were 50.15\% and 50.51\%, respectively. The urbanised stations were located in four directions: Beijing to Qinhuangdao, Beijing to Tanggu, Beijing to Shijiazhuang and Beijing to Zhangjiakou. 
The farmland stations were distributed in the western, southern and eastern parts of the Jing-Jin-Ji region. The proportions of the farmland area for these stations were between 55\% and 75\% (Figure 2). Three farmland stations (Zhangbei, Huailai and Yuxian) were located in the northwestern part of the plain and four farmland stations (Langfang, Rongyuan, Huanghua and Nangong) were located in the southern part. The land use type for Laoting station was mainly farmland, located in the northeastern part of the plain (Figure 1).

\subsection{Changes in $\mathrm{ET}_{0}$ of stations with different land use types}

Figure $3 \mathrm{a}$ shows the time series of annual $\mathrm{ET}_{0}$ in the study area. The lowest annual $\mathrm{ET}_{0}$ was $909.7 \mathrm{~mm}$ in 2003, whereas the highest annual $\mathrm{ET}_{0}$ was $1050.5 \mathrm{~mm}$ in 2009. The 5-year moving average annual $\mathrm{ET}_{0}$ of the 22 selected meteorological stations showed an increasing trend from 1991 to 2015. Furthermore, linear regression analysis indicated that $\mathrm{ET}_{0}$ significantly increased $(p<0.05)$ at a rate of $7.4 \mathrm{~mm}$ per decade in the Jing-Jin-Ji region.
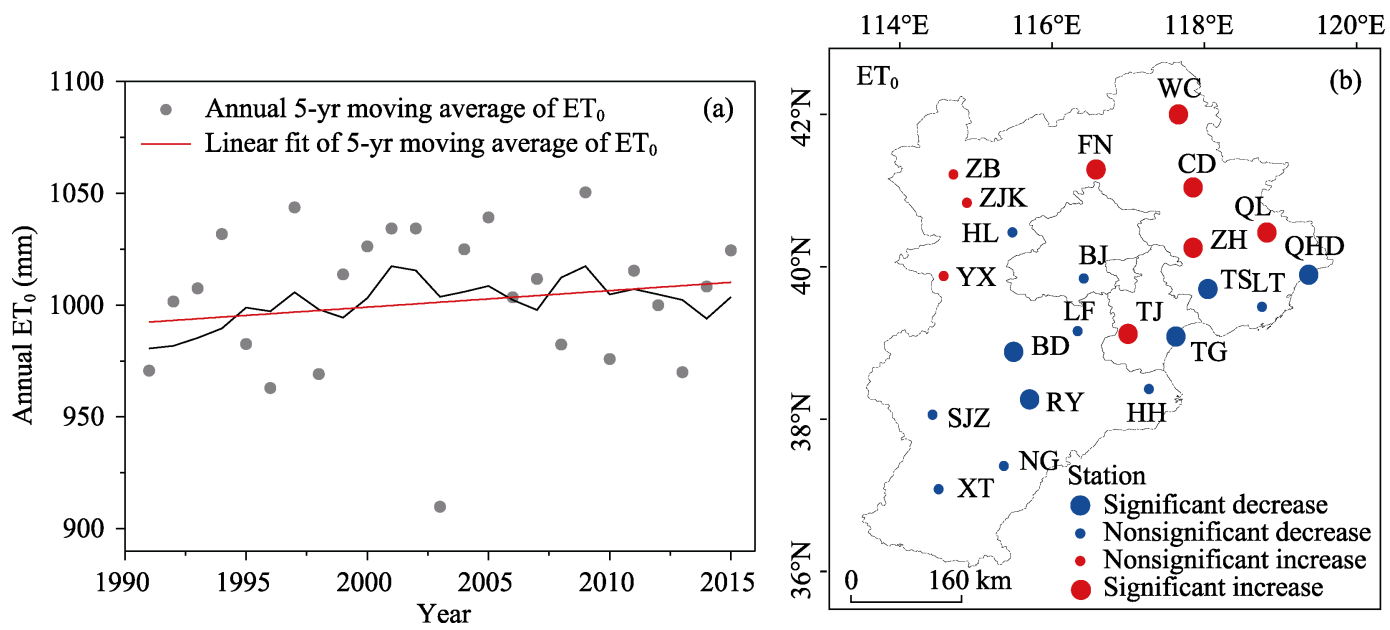

Figure 3 Annual change (a) and spatial change (b) in $\mathrm{ET}_{0}$ in the Jing-Jin-Ji region from 1991 to 2015

The change in $\mathrm{ET}_{0}$ showed a spatial difference with different land use types (Figure $3 \mathrm{~b}$ ). The $\mathrm{ET}_{0}$ of most stations increased in the northern part (north of $40^{\circ} \mathrm{N}$ ), but decreased in the southern (south of $40^{\circ} \mathrm{N}$ ). The $\mathrm{ET}_{0}$ of the four natural stations in the northern Yanshan mountainous area showed an increasing trend. The $Z$ value obtained from the MK trend test for the natural stations ranged from 2.58 to 3.373 , located above the red dashed line in Figure 4, indicating a significant increase in $\mathrm{ET}_{0}$. The $\mathrm{ET}_{0}$ of the six farmland stations in the eastern and southern parts showed a decreasing trend, which was not significant except for that related to Raoyang station located on the central plain (Figures $3 \mathrm{~b}$ and 4 ). However, $\mathrm{ET}_{0}$ increased at Zhangbei and Yuxian stations in the western mountainous area. Furthermore, $\mathrm{ET}_{0}$ showed a significant decreasing trend at stations that had an urbanisation percentage $>80 \%$, while $\mathrm{ET}_{0}$ showed an increasing trend at Zhangjiakou, Zunhua and Tianjin stations. Figure 4 shows that, among the stations for which a decreasing $E_{0}$ trend was noted, the trend at urban stations was more significant than that at farmland stations. The $Z$ value obtained from the MK trend test for the urban stations ranged from -4.663 to -1.439 , while that for farmland stations ranged from -2.927 and -0.248 . 
Similar findings have been reported for $\mathrm{ET}_{0}$ trends in northern China (Han and $\mathrm{Hu}, 2012$ ); an obvious decreasing trend in $\mathrm{ET}_{0}$ was noted as a result of extensive irrigation in the $\mathrm{arid} / \mathrm{semi}$-arid areas. Moreover, $\mathrm{Xu}$ et al. (2015) observed a decreasing trend in $\mathrm{ET}_{0}$ at agricultural and urban stations in the Jinghe River Basin. However, in the case of natural stations, $\mathrm{Xu}$ et al. (2015) noted a decreasing $\mathrm{ET}_{0}$ trend, which is in contrast with our findings.

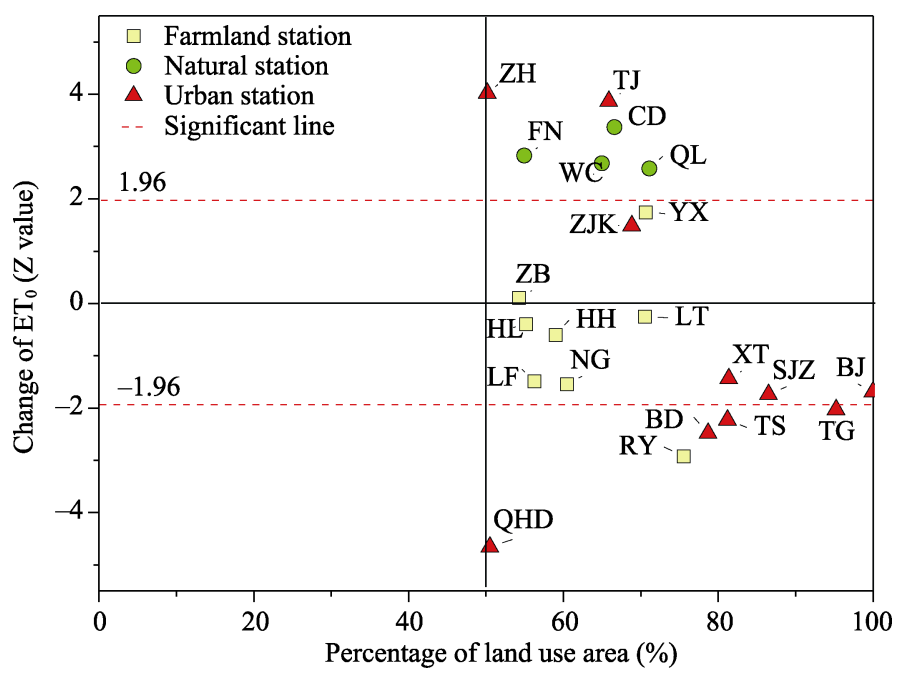

Figure 4 Relationship between $\mathrm{ET}_{0}$ changes and land use patterns in 2015

\subsection{Meteorological parameter changes for different land use types}

Figure 5 illustrates the spatial distribution of the changing trend of meteorological parameters in the study area. Wind speed was noted to be significantly increased at all the natural stations, leading to significant $\mathrm{ET}_{0}$ increase at these stations (Figure 5a). On the other hand, wind speed at most farmland and urban stations decreased significantly, thus causing $\mathrm{ET}_{0}$ decrease at these stations. With the exception of Zunhua and Hanghua stations, sunshine duration was particularly decreased at 12 of the 20 farmland and urban stations, thus causing a significant $\mathrm{ET}_{0}$ decreasing trend at these stations (Figure 5b). With respect to relative humidity and air temperature, no obvious consistent changes were noted at the stations. In terms of relative humidity at all the stations, we noted that two natural, three farmland and three urban stations showed increasing trend, causing an increasing $\mathrm{ET}_{0}$ trend, while two natural, five farmland and seven urban stations showed a downward trend, causing a decreasing $\mathrm{ET}_{0}$ trend (Figure $5 \mathrm{c}$ ). The trend of air temperature was roughly opposite to the relative humidity. The air temperature decreased at the stations with upward trend in relative humidity. Therefore, in terms of air temperature, one natural, five farmland and five urban stations showed an increasing trend, whereas three natural, three farmland and five urban stations showed a decreasing trend (Figure 5d).

In addition to human activity, meteorological parameters play a decisive role in spatial variations in $\mathrm{ET}_{0}$ (Zhao et al., 2014). Li et al. (2017) observed climate change to have a more significant effect on ET than land use change. Wind speed is generally expected to have low values in urban areas than in rural areas because wind is blocked by high buildings in urban areas. Jiang et al. (2009) observed that a decline in average wind speed is closely 

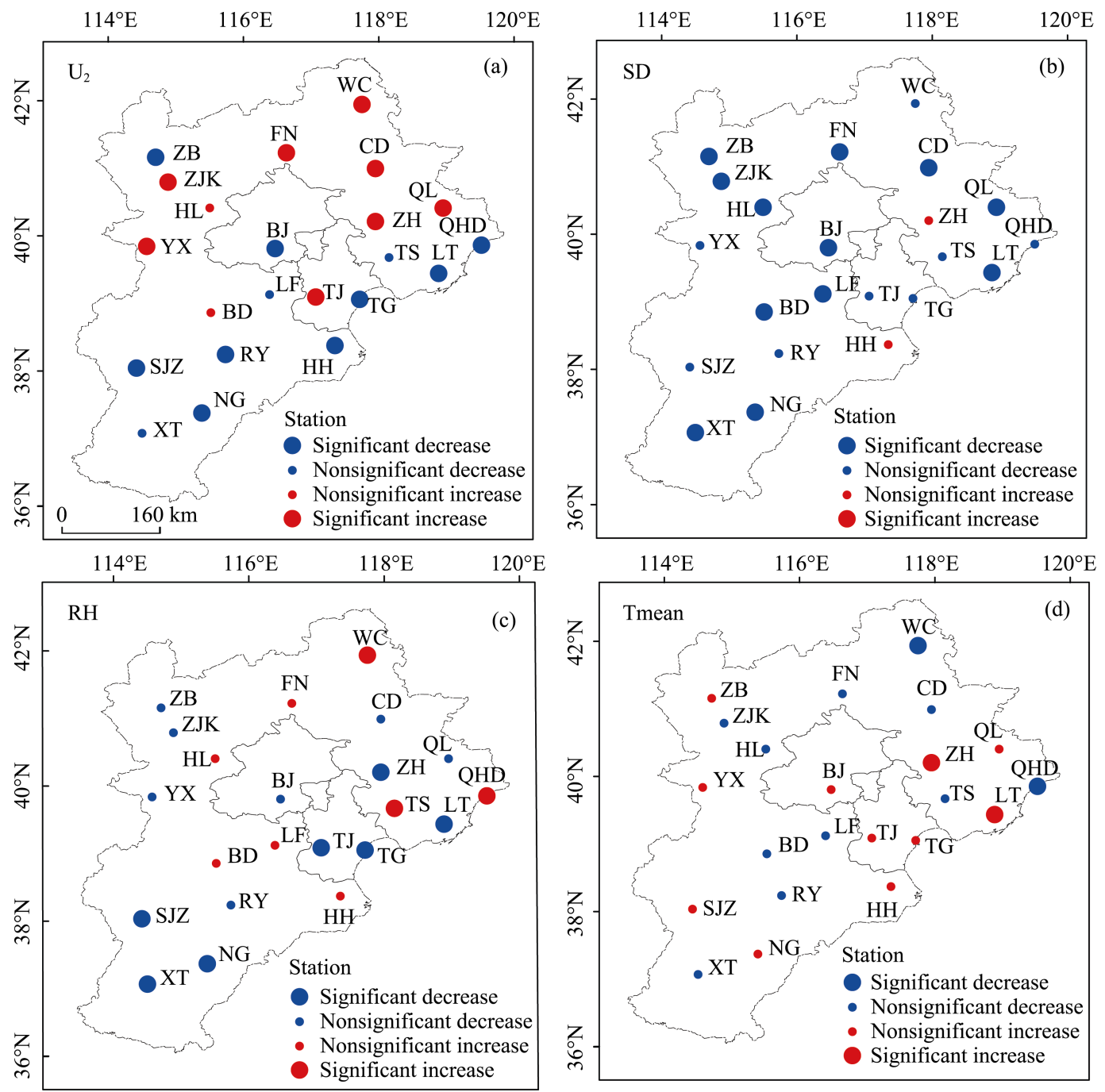

Figure 5 Changes of meteorological parameters at 22 stations: (a) wind speed, (b) sunshine duration, (c) relative humidity and (d) average air temperature

related to not only weakened winter and summer monsoons but also increasing urbanisation in China. Han et al. (2016) demonstrated that surface wind speed is lowered by farmland and that wind speed values were significantly low at farmland stations. With respect to sunshine duration, Zhang et al. (2004) noted that low values can be attributed to increasing air pollution or high concentration of aerosols in the atmosphere. Furthermore, Liu et al. (2010) found that the aerosol index increased significantly after 1989 in the Haihe River Basin and that this index was higher in areas with higher population density than in those with lower population density. They concluded that an increase in aerosol concentrations in the atmosphere caused by human activities results in low values for sunshine duration and solar radiation. Zhang et al. (2006) also indicated that increasing air pollution may result in reduced sunshine duration in eastern China. Additionally, changes in air temperature can be attributed to factors such as reduction in sunshine duration or irrigation, depending on the land use type. Han and Yang (2013) studied the cooling effect of irrigation in Xinjiang, China, 
and noted this effect to influence changes in air temperature in the region. In the context of this study, low air temperatures for farmland stations may be attributed to irrigation. Thus, different types of topography and land use largely affect the distribution of wind speed, temperature and other meteorological parameters in a region (Jiang et al., 2009; Zhu et al., 2012). Based on this relationship between land use types and meteorological parameters, we proceeded to analyse the effect of these parameters on variations in $\mathrm{ET}_{0}$, using the multiple regression equation mentioned in section 2.5 .

\subsection{Dominant meteorological parameters affecting $\mathbf{E T}_{\mathbf{0}}$ of different land use types}

In general, the dominant meteorological parameters affecting $\mathrm{ET}_{0}$ at most stations can be ranked as wind speed $>$ sunshine duration $>$ air temperature $>$ relative humidity (Figure 6). However, at each station, the contribution of each parameter to $\mathrm{ET}_{0}$ was different. Wind speed was the most dominant parameter affecting $\mathrm{ET}_{0}$ at the four natural stations, with its contribution ranging from $44 \%$ to $55 \%$ (Figure 6). The second dominant meteorological parameter affecting $\mathrm{ET}_{0}$ at Weichang and Fengning stations was air temperature, while that at Chengde and Qinglong stations was sunshine duration.

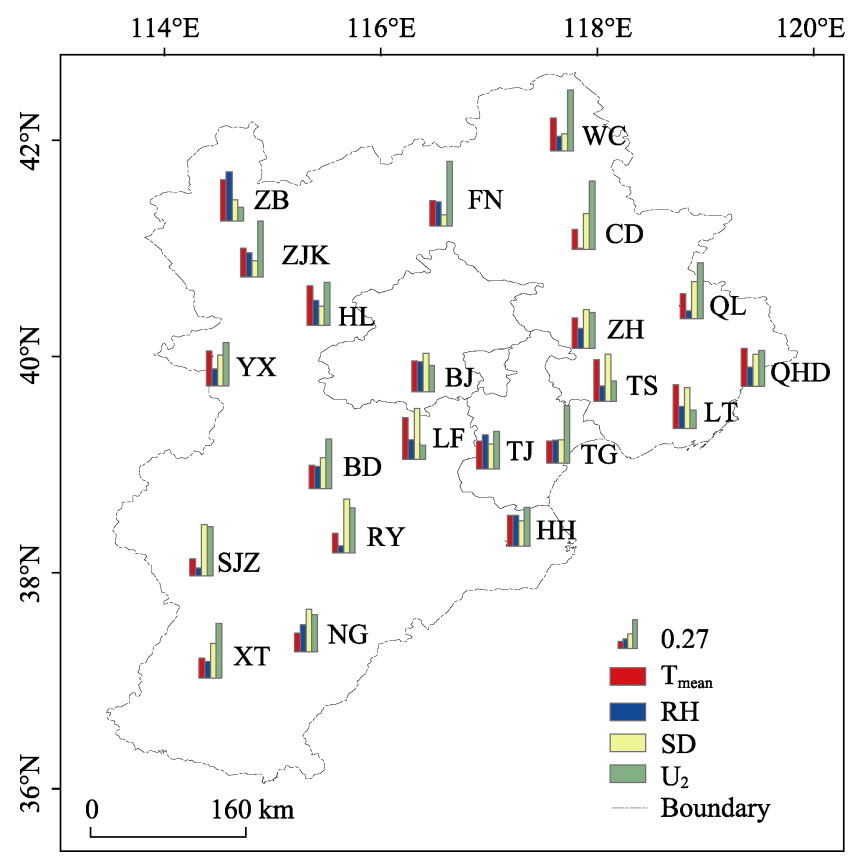

Figure 6 Relative contributions of meteorological parameters to $\mathrm{ET}_{0}$ of different land use types in the study area

As for the farmland stations, the main parameters controlling $\mathrm{ET}_{0}$ changes were different. The dominant parameters at Huanghua, Yuxian and Huailai stations were wind speed and air temperature. For Langfang and Laoting, the contribution of sunshine duration and air temperature to $\mathrm{ET}_{0}$ changes was $>65 \%$. Furthermore, sunshine duration and wind speed were the dominant meteorological parameters affecting ET $_{0}$ at Raoyang and Nangong stations, and relative humidity and air temperature were the dominant parameters affecting $\mathrm{ET}_{0}$ at Zhangbei station.

With respect to the urban stations, the dominant parameters affecting $\mathrm{ET}_{0}$ at most stations 
were wind speed and sunshine duration. At Tianjin, Zunhua and Zhangjiakou stations, high wind speed values played an important role in the increasing $\mathrm{ET}_{0}$ trend. The dominant meteorological parameters affecting $\mathrm{ET}_{0}$ at Beijing and Tangshan stations were sunshine duration and air temperature, while those at Qinhuangdao station were air temperature and wind speed.

Our findings show that different types of land use significantly impact $\mathrm{ET}_{0}$ in a region; however, quantitatively assessing this impact is not easy. The influence of human activities, such as air pollution and land use change, on $\mathrm{ET}_{0}$ is ultimately reflected through their influence on meteorological parameters (Zhao et al., 2014). A large number of studies have assessed the attribution of $\mathrm{ET}_{0}$ to meteorological parameters; for example, wind speed was found to be the main parameter affecting $\mathrm{ET}_{0}$ in the Haihe River Basin (Wang et al., 2011), the Huanghe River watershed (Ma et al., 2012), southwestern China (Li et al., 2014) and the Jinghe River Basin (Xu et al., 2015). However, few studies have focused on the relationship between different land use types and $\mathrm{ET}_{0}$. Because of this limitation, it was difficult to compare and assess the accuracy of our findings. Therefore, future studies should focus on verifying these findings on a larger spatial scale.

\section{Conclusions}

Variations in $\mathrm{ET}_{0}$ and meteorological variables in different land use types were analysed using climate data from 22 meteorological stations in the Jing-Jin-Ji region for the period 1991-2015. Furthermore, land use data for 2015 was used to identify the dominant land use pattern at each meteorological station. The following conclusions may be drawn from this study:

(1) The meteorological stations were classified into urban (10 stations), farmland (8 stations) and natural stations (4 stations). The natural stations were located in the northern mountainous area. Most urban stations were distributed in the North China Plain and coastal area. The farmland stations were located in northwestern part of the plain area. Human activities, including urbanisation, agricultural practices and forest restoration, determined the land use type in the study area.

(2) The annual $\mathrm{ET}_{0}$ increased significantly at a rate of $7.4 \mathrm{~mm}$ per decade from 1991 to 2015. However, the spatial distribution of $\mathrm{ET}_{0}$ variations was different for different land use types. $\mathrm{ET}_{0}$ at natural stations increased significantly; the $Z$ value obtained from the MK trend test for the four natural stations ranged from 2.58 to 3.373. $\mathrm{ET}_{0}$ at most urban and farmland stations decreased in the coastal and plain areas; the decreasing $\mathrm{ET}_{0}$ trend at the urban stations was greater than that at the farmland stations. The $Z$ value for the urban stations ranged from -4.663 to -1.439 , whereas that for the farmland stations ranged from -2.927 and -0.248 .

(3) The dominant meteorological parameters affecting $\mathrm{ET}_{0}$ at most stations were ranked as follows: wind speed $>$ sunshine duration $>$ air temperature $>$ relative humidity. The dominant parameters were wind speed at all the natural stations, and wind speed and sunshine duration at most urban stations. However, parameters affecting $\mathrm{ET}_{0}$ at the farmland stations varied.

Thus, our study shows that land use types in a region influence meteorological parameters such as wind speed and air temperature, which in turn influence $\mathrm{ET}_{0}$. This understanding of 
the relationship between different land use types, meteorological parameters and $\mathrm{ET}_{0}$ provides a basis for understanding a region's hydrology and for future studies evaluating $\mathrm{ET}_{0}$ on a larger spatial scale. Furthermore, the findings of this study can be used to devise appropriate measures for sustainable land use practice and water resource management.

\section{References}

Allen R G, Pereira, L S, Raes D et al., 1998. Crop Evapotranspiration: Guidelines for computing crop water requirements, FAO Irrigation and Drainage Paper No.56. FAO, Rome, Italy.

Boisier J P, de Noblet-Ducoudré N, Ciais P, 2014. Historical land-use-induced evapotranspiration changes estimated from present-day observations and reconstructed land-cover maps. Hydrology and Earth System Sciences, 18(9): 3571-3590.

Dong J, Zhuang D F, Xu X L et al., 2008. Integrated evaluation of urban development suitability based on remote sensing and GIS techniques: A case study in Jingjinji area, China. Sensors, 8(9): 5975-5986.

Feng Z M, Liu D W, 2006. A study on water resources carrying capacity in Jing-Jin-Ji Region. Journal of Natural Resources, 21(5): 689-699. (in Chinese)

Gong L B, Xu C Y, Chen D L et al., 2006. Sensitivity of the Penman-Monteith reference evapotranspiration to key climatic variables in the Changjiang (Yangtze River) basin. Journal of Hydrology, 329(3): 620-629.

Han J Y, Wang J H, Zhao Y et al., 2018. Spatio-temporal variation of potential evapotranspiration and climatic drivers in the Jing-Jin-Ji region, North China. Agricultural and Forest Meteorology, 256: 75-83.

Han S J, Hu H P, 2012. Spatial variations and temporal changes in potential evaporation in the Tarim Basin, northwest China (1960-2006): Influenced by irrigation? Hydrological Processes, 26(20): 3041-3051.

Han S J, Tang Q H, Zhang X Z et al., 2016. Surface wind observations affected by agricultural development over Northwest China. Environmental Research Letters, 11(5). doi: 10.1088/1748-9326/11/5/054014.

Han S J, Xu D, Wang S L, 2012. Decreasing potential evaporation trends in China from 1956 to 2005: Accelerated in regions with significant agricultural influence? Agricultural and Forest Meteorology, 154: 44-56.

Han S J, Yang Z Y, 2013. Cooling effect of agricultural irrigation over Xinjiang, Northwest China from 1959 to 2006. Environmental Research Letters, 8(2): doi: 10.1088/1748-9326/8/2/024039.

Huang Y H, Wang J H, Jiang D et al., 2014. Surface water deficiency zoning of China based on surface water deficit index (SWDI). Water Resources, 41(4): 372-378.

Huo Z L, Dai X Q, Feng S Y et al., 2013. Effect of climate change on reference evapotranspiration and aridity index in arid region of China. Journal of Hydrology, 492: 24-34.

Jhajharia D, Shrivastava S K, Sarkar D et al., 2009. Temporal characteristics of pan evaporation trends under the humid conditions of northeast India. Agricultural and Forest Meteorology, 149(5): 763-770.

Jiang B, Liang S L, Yuan W P, 2015. Observational evidence for impacts of vegetation change on local surface climate over northern China using the Granger Causality test. Journal of Geophysical Research, 120(1): 1-12.

Jiang Y, Luo Y, Zhao Z C et al., 2010. Changes in wind speed over China during 1956-2004. Theoretical and Applied Climatology, 99(3/4): 421-430.

Kundu S, Khare D, Mondal A, 2017. Past, present and future land use changes and their impact on water balance. Journal of Environmental Management, 197: 582-596.

Li G, Zhang F M, Jing Y S et al., 2017. Response of evapotranspiration to changes in land use and land cover and climate in China during 2001-2013. Science of The Total Environment, 596: 256-265.

Li Z X, Feng Q, Liu W et al., 2014. Spatial and temporal trend of potential evapotranspiration and related driving forces in southwestern China, during 1961-2009. Quaternary International, 336: 127-144.

Liu C M, Liu X M, Zheng H X et al., 2010. Change of the solar radiation and its causes in the Haihe River Basin and surrounding areas. Journal of Geographical Sciences, 20(4): 569-580.

Liu M L, Tian H Q, Chen G S et al., 2008. Effects of land-use and land-cover change on evapotranspiration and water yield in China during 1900-2000. Journal of the American Water Resources Association, 44(5): 
1193-1207.

Liu W J, Hong Y, Khan S I et al., 2010. Actual evapotranspiration estimation for different land use and land cover in urban regions using Landsat 5 data. Journal of Applied Remote Sensing, 4(1). doi: 10.1117/1.3525566.

Ma X N, Zhang M J, Li Y J et al., 2012. Decreasing potential evapotranspiration in the Huanghe River watershed in climate warming during 1960-2010. Journal of Geographical Sciences, 22(6): 977-988.

Olchev A, Ibrom A, Priess J et al., 2008. Effects of land-use changes on evapotranspiration of tropical rain forest margin area in Central Sulawesi (Indonesia): Modelling study with a regional SVAT model. Ecological Modelling, 212(1/2): 131-137.

Wang J H, Wang Q M, Zhao Y et al., 2015. Temporal and spatial characteristics of pan evaporation trends and their attribution to meteorological drivers in the Three-River Source Region, China. Journal of Geophysical Research: Atmospheres, 120(13): 6391-6408.

Wang Q M, Wang J H et al., 2016. Reference evapotranspiration trends from 1980 to 2012 and their attribution to meteorological drivers in the Three-River Source Region, China. International Journal of Climatology, 36(11): 3759-3769.

Wang W G, Peng S Z, Yang T et al., 2011. Spatial and temporal characteristics of reference evapotranspiration trends in the Haihe River basin, China. Journal of Hydrologic Engineering, 16(3): 239-252.

Xu L H, Shi Z J, Wang Y H et al., 2015. Spatiotemporal variation and driving forces of reference evapotranspiration in Jing River Basin, northwest China. Hydrological Processes, 29(23): 4846-4862.

Zhang Y. L, Qin B. Q, Chen W M, 2004. Analysis of 40 year records of solar radiation data in Shanghai, Nanjing and Hangzhou in eastern China. Theoretical and Applied Climatology, 78(4): 217-227.

Zhao L L, Xia J, Sobkowiak L et al., 2014. Climatic characteristics of reference evapotranspiration in the Hai River Basin and their attribution. Water, 6(6): 1482-1499.

Zhu G F, He Y Q, Pu T et al., 2012. Spatial distribution and temporal trends in potential evapotranspiration over Hengduan Mountains region from 1960 to 2009. Journal of Geographical Sciences, 22(1): 71-85.

Zou M Z, Niu J, Kang S Z et al., 2017. The contribution of human agricultural activities to increasing evapotranspiration is significantly greater than climate change effect over Heihe agricultural region. Scientific Reports, 7(1). doi: 10.1038/s41598-017-08952-5. 